\title{
The Bibliography and History of Risk Management : Some Preliminary Observations
}

\author{
by G. Neil Crockford *
}

\section{Introduction}

The literature of a subject constitutes a record of its evolution, and of the different aspects of it which have received particular attention at various stages of its development. Risk management has now been a term in general use for some thirty years, long enough for it to have developed from a largely theoretical approach to risk problems fostered by a handful of academics and far-seeing insurance managers in industry into a generally-accepted approach to the practical solution of certain types of problem in the industrial and commercial world, and in local government.

A study of the literature of risk management will therefore be useful in tracing the development of the orthodox concept of it which is put into practice with varying degrees of skill, understanding and enthusiasm by what are now commonly called risk managers in industry, and which is taught and examined by universities and professional insurance bodies. ${ }^{1}$ At the same time, light might be shed on the areas of disagreement about the scope of risk management, and who should be primarily responsible for putting it into practice, and on the changing importance of different facets of risk management such as self-insurance and loss control, for example, in response to the development of risk management theory, the attitude of insurers and their regulatory bodies and the economic climate in which insurers and customers in the industrial and commercial world had to operate.

This paper, as its title indicates, makes no claim to be such a study, which would be no small undertaking, partly for reasons which are examined below, partly because, although the monograph literature is not great, the wide application of risk management has led to its discussion in a very large number of articles in journals and other periodicals both inside and outside the insurance world. While a large number of these

*Information Services Manager, Bowring (U.K.) Ltd., London.

1 The Insurance Institute of America first drew up a curriculum for its ARM designation in 1965. This year, 1982, the syllabus for the Fellowship examination of the Chartered Insurance Institute in the U.K. includes a risk management paper among its options for the first time. 
do no more than repeat the basic principles of risk management, the net must still be spread very wide to capture all those that have some significance in the development of risk management ideas.

As a preliminary to such a study, this paper, after a discussion of some of the major problems of definition raised by any research into risk management, reports the results of a quantitative study of the articles on risk management subjects appearing in two journals during the period 1956 to 1980 . The journals selected were The Journal of Risk and Insurance, which changed its title from The Journal of Insurance in 1964, and which is a learned journal with a largely academic input, and Risk Management (formerly The National Insurance Buyer), which is published by the Risk and Insurance Management Society (R.I.M.S.), the professional association of American risk managers. This journal is therefore directed towards practising risk managers, who are represented among the contributors alongside those from the academic world.

The number and subject matter of articles in these journals are compared and some conclusions drawn about developments in risk management thinking at the theoretical and practical levels by reference to events in the general and bibliographical history of the subject.

\section{Some problems of definition}

Research into risk management immediately encounters some basic problems of definition. There is still no general agreement on where the boundaries of the subject lie, and a satisfactory definition of risk management is notoriously difficult to formulate. In the first textbook on the subject, Mehr and Hedges [8] used a definition which reflected a close identification with insurance management : " the management of those risks for which the organisation, principles and techniques appropriate to insurance management are useful". They have been followed by many who hold the view that the application of risk management is limited to the field of pure risks. Some misgivings about the adequacy of a definition in these terms may possibly be detected in the approach of McCahill [7] in an article which was influential in bringing risk management theory to the attention of a wider management audience. "The term " risk management" ", he writes, "encompasses primarily those activities performed to prevent accidental loss".

If the term 'accidental loss', which is undefined in the article, can be taken to approximate to pure risk, then this definition implies that risk management may have some interest, albeit a secondary one, in risks which lie across the border in the field of speculative risk ${ }^{2}$. Some writers go much further and deny that the pure risk/speculative risk boundary has any relevance for risk management. Representative of this view are Bannister and Bawcutt [1], who define risk management as " the identification, measurement and economic control of risks that threaten the assets and earnings of a business or other enterprise". This approach stresses the management half of the

2 Despite the clear distinction in theory between pure and speculative risks, this border may in practice be very difficult to locate. For an example, see Crockford [2], p. 12. 
term ' risk management'. The stages of risk management listed in this definition can be equated with the process of definition of a problem, evaluation of possible solutions and selection of the most appropriate which is central to all management decisions. If it is accepted that it is the aim of management to see that as far as possible an enterprise runs only those risks, whether pure or speculative, which it chooses to run, and if the methods it uses in considering risks of both kinds are the same, then it is possible to make the extreme statement that "all management is risk management" (Crockford [2]). Practice, however, shows no sign of following theory to these lengths. The function of the risk manager remains broadly what it was when the Association of Insurance Managers in Industry and Commerce became the Association of Risk and Insurance Managers in Industry and Commerce in 1974 and when the American Society of Insurance Management became R.I.M.S. shortly afterwards. The Geneva Association's [4] observation that "une vision trop rationaliste de la fonction du risk manager reviendrait à ce qu'il se substitue tout simplement au directeur général " is clearly correct. The risk manager has not become chief executive, however, nor has the chief executive taken over the risk manager's function. Operational convenience continues to dictate that pure and speculative risks should be handled by different functions within a company, even though theory may argue for them being managed as one.

For practical purposes, therefore, the emphasis of risk management continues to be on pure risks. This, in turn, relieves the researcher of the need to include the whole of the literature of management in a study of risk management literature. Problems of definition do not stop here, however. Risk management is very much concerned with loss control, but each aspect of loss control - fire prevention, safety, security, liability loss control among them - will have its own specialist literature. Each of these may be considered a branch of risk management literature. Are they all to be surveyed in their entirety? Similarly, since insurance remains the primary funding mechanism for residual pure risks, must the whole literature of insurance be included ? Some limits must obviously be set, but where ? One is forced to the conclusion that the only workable definition of risk management for the present purpose is the unsatisfactory one that risk management literature is that which demonstrates an awareness of risk management.

Even this does not solve all the problems of definition. The theories of risk management which have emerged from the insurance world have very largely ignored, and have been ignored by, the forms of risk management which have been developed in the engineering world ${ }^{3}$. It would be necessary to decide whether or not the literature from this area forms part of the literature of risk management to be studied. A possible solution would be to treat this literature as that of a specialist field of loss control and to subject it to the same criteria for admission as the literature of, say, fire prevention.

3 It is encouraging that a research project to identify sources of risk management education for engineers is to be carried out during 1982 by the Centre for Insurance Research at the City of London Polytechnic, under Peter Franklin, commissioned by the Geneva Association. 


\section{The evolution of interest in risk management}

In the present, small-scale study, these problems of definition of the field have not arisen, or perhaps it would be truer to say that they have been avoided. Selection for study of two journals which have broadened their scope from insurance to include risk management reduces the problem of defining risk management material to one merely of excluding articles which are wholly concerned with insurance, and, in the case of The Journal of Risk and Insurance, selection was even further simplified by considering as risk management papers those so classified by the editors in the cumulative index for the years in question.

Figures 1 and 2 show the total number of articles published in each of the publications, expressed as a running five-year average over the period under consideration. Comparison of the two tables demonstrates clearly by how much academic interest in risk management preceded that of insurance buyers. The term 'risk management' appears to have come into use in the early 1950s. Snider [10], writing in 1956, records the fact that there was then no textbook on risk management, no business school in the United States offering a risk management major, and only one college there giving a course in risk management. One may therefore deduce that interest in risk management among insurance academics at that time was not widespread. There is supporting evidence for such a deduction in the fact that no article on risk management appeared in The Journal of Risk and Insurance (JRI), or its predecessor titles, before that same year, 1956.4

Over the next few years, however, Figure 1 testifies to a rapid increase in academic writing on risk management. The largest number of risk management papers (nine) appeared in JRI in 1963, and the Figure shows that the period of maximum academic interest in risk management topics appears to have lasted from then until 1967, after which date there was a steady decline. External evidence confirms that this was a period of particular activity in the documentation of risk management. The textbook Snider had desired to see, and which Mehr and Hedges [8] had been working on since 1955, appeared in 1963, and was followed in 1964 by another influential one, by Williams and Heins [11]. So far, the development of risk management would seem to have been wholly an American phenomenon. What appear to have been the earliest articles on risk management to have been published in the United Kingdom, however, date from 1967 (Horrigan and Dinsdale [6]). They were a collaboration between Horrigan, a noted pioneer of risk management in Britain, whose 1969 paper [5] became a landmark in the development of British risk management, and Dinsdale, at that time a Visiting Professor at the University of Texas.

In 1965, as we have seen, risk management, through the efforts of the Insurance Institute of America, began to figure in professional education.

The decline revealed by the Figure since 1967 was a marked one, and it is noteworthy that in the period 1977-1980 inclusive, only two risk management papers were

4 One excludes from consideration a 1943 paper on "The Impact of the War on Workmen's Compensation Underwriting and Loss Prevention", which is classified under the risk management section of JRI's subject index. 


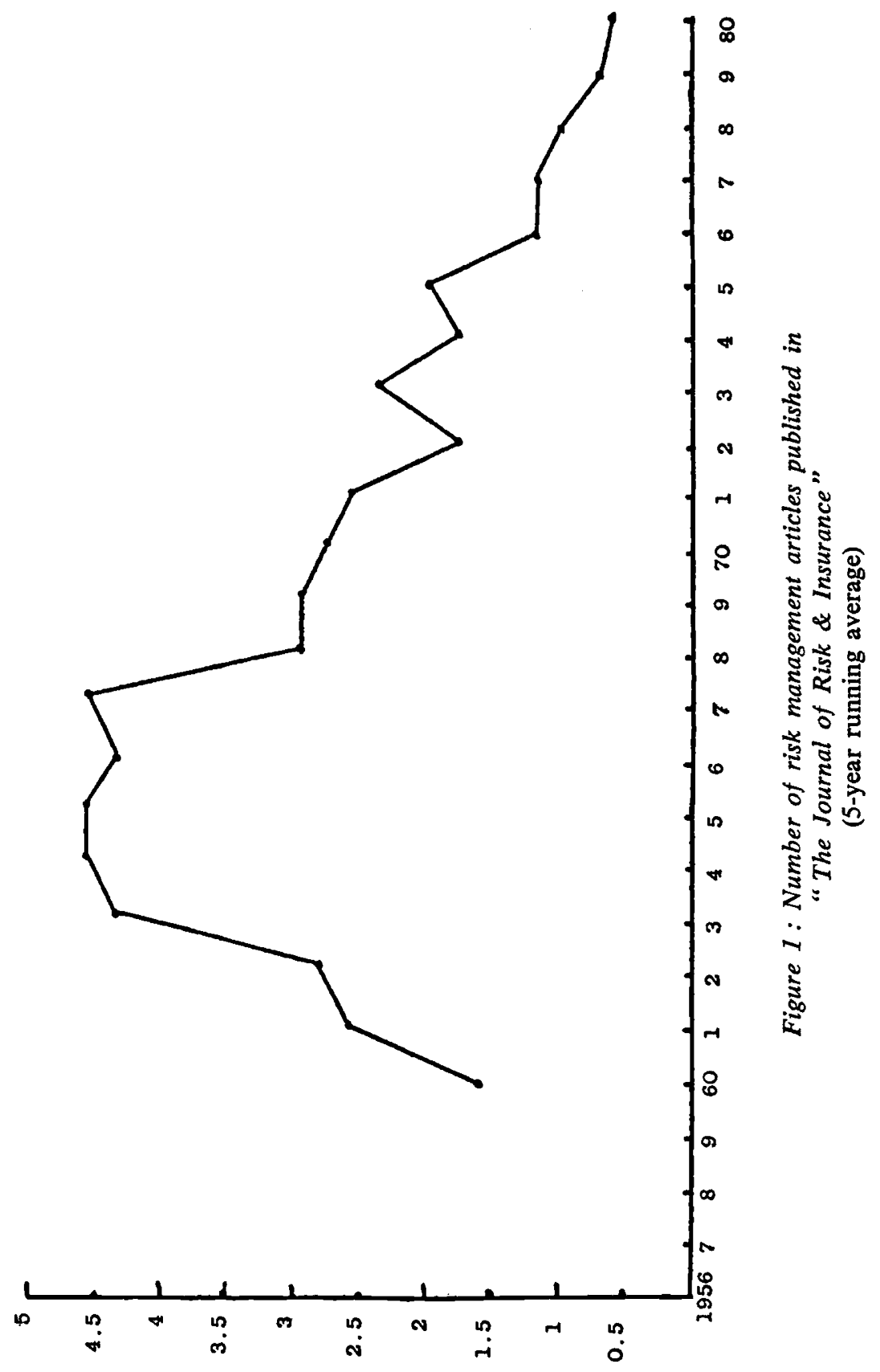


published in JRI, both of them in 1978. Discounting explanations involving editorial bias or a lower standard of writing upon risk management than upon other insurance topics, for which there is no evidence, one is led to conclude that the table reflects a slackening off of academic concern with risk management. Possibly the early establishment of a recognised methodology of risk management and the essential simplicity of its aims led academics to concentrate on more theoretical aspects of risk and economics in the insurance sphere, and to leave the practical elaboration of risk management to the practitioners, or at any rate to channel their own contributions towards journals whose readership was more interested in and acquainted with practice rather than with theory.

Risk Management is such a publication, and Figure 2 seems to show that this is what occurred. During the years up to and including those of peak academic interest, the number of articles on risk management rather than insurance topics in this practitioners' publication showed a steady level of interest, with only a gentle upwards trend. The rapid spurt of interest came in the years from 1970, when the decline in Figure 1 had set in. The running average index in Figure 2 is still rising in 1980, although the peak number of articles (42) was reached in 1976.

The pattern traced in Figure 2 suggests that early academic attention to risk management brought about a steady educative process represented by the regular appearance of articles about risk management, which finally resulted in a triple change, first in the insurance buyer's conception of his role within his company, secondly in the recognition within companies of this change of function, and thirdly in the increasing extent to which risk managers are seen as part of the financial function of a company. Once this educative effort had borne fruit, interest in risk management became much greater, and the contents of the publication reflected this increase. The change of emphasis from theory to practice as the insurance buyer became a convert to risk management is illustrated by the publication of a detailed risk management case study (Rosenbloom [9]) in 1972.

The expansion of risk management awareness in the early seventies in the United States which Figure 2 indicates was matched by a widening of interest in Europe. Management Centre Europe introduced the subject into their annual insurance conference in 1971, and followed it up with their first course devoted to the subject in Brussels in 1972. These years, too, saw a proliferation of risk management consultancies in the U.K., one of which, Keith Shipton Developments, was to publish a very large amount of risk management-related material. With a growing awareness of the widening responsibilities of the insurance buyer as he evolved into a risk manager, and a desire for the buyer's voice to be heard in E.E.C. circles, a number of European insurance management organisations came together in 1974 to take the first steps towards the formation of the "Association Européenne des Assurés de l'Industrie" (A.E.A.I.).

It is as yet too early to say whether the slight reduction in the number of risk management articles since 1976 is evidence of a detectable falling-off of interest in the subject, or whether we are witnessing a new stabilisation at a higher level. 


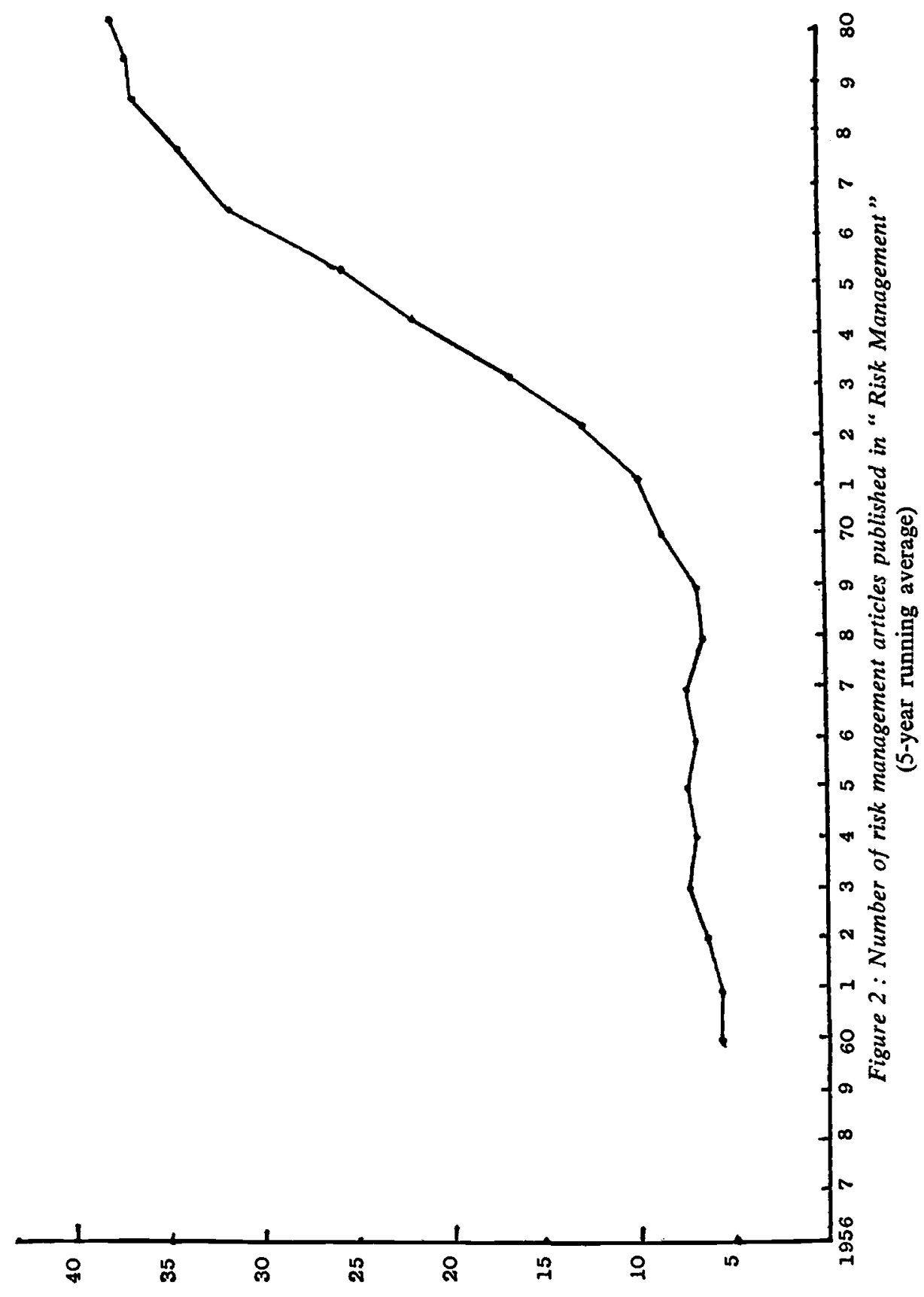




\section{Analysis of subject matter}

Table 1 gives an indication of the subject matter of the contributions to the two periodicals. Selection of categories posed some problems, since to use too many would spread what is already a small sample too thinly for useful analysis. At the same time, there must be sufficient for changing levels of interest in each of the broad divisions of the subject to be noted. Six categories were finally selected, and while they may perhaps appear arbitrary, they were in large measure decided by the articles themselves which seemed to group themselves conveniently into these classes.

The six are: loss control, premium minimisation (a category which includes self-insurance and deductibles, retrospective rating plans and the like), captive insurance companies ${ }^{5}$, risk management organisation (which includes not only the structure and management of a risk management department but also the application of risk management techniques to particular problems of insurance buying, as the two aspects proved to be closely allied, and impossible to segregate consistently), decision theory and quantitative techniques, and risk management education. The first four categories emphasize the practical application of risk management; the last two its theoretical content.

The small sample provided by The Journal of Risk and Insurance must lead to caution in analysing the nature of the articles in it, but it is immediately apparent that in both journals by far the largest body of material comes into the risk management organisation category. This suggests that academics and practitioners alike found that the most compelling aspect of risk management lay in its application to the solution of specific insurance-related problems, and in establishing the best form of organisational structure to reflect the change of emphasis from the straightforward purchase of insurance to a risk management approach where insurance becomes not the automatic response to a static risk problem, but a technique of financing to be resorted to when other methods of avoidance, control and financing are impossible or inappropriate.

Apart from this shared interest, it is not remarkable that the academic world, represented by JRI, is much more concerned with the more theoretical aspects of the subject than the practising risk manager. In the 25 years under consideration the proportion of papers on decision theory and quantitative methods appearing in JRI was twice that in Risk Management. In the risk management education category, the disparity is even greater, for while only $2.1 \%$ of articles over the period in Risk Management were concerned with this topics, it accounts for a quarter of all those appearing in The Journal of Risk and Insurance.

It comes as no surprise that education is of more immediate interest to the academic author, but it is interesting that in both publications the preponderance of papers in this category appeared during the period 1956-71, which, as we have seen, was the period in which insurance buyers were being steadily educated into risk

5 This category might logically form part of the preceding one, but since there is a specialist literature on captives, it has been kept separate. 
Table 1: Percentage of risk management articles

published in "The Journal of Risk \& Insurance" and in "Risk Management" (1956-1980 by Subject Category)

\begin{tabular}{|c|c|c|c|c|}
\hline \multirow{2}{*}{ 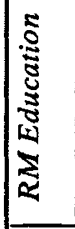 } & ฉิ & 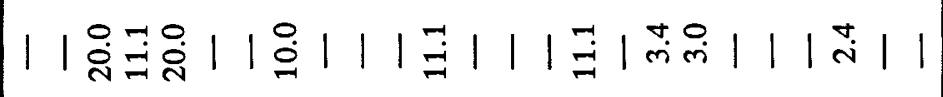 & $\vec{i}$ & $\dot{m}$ \\
\hline & 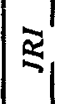 & 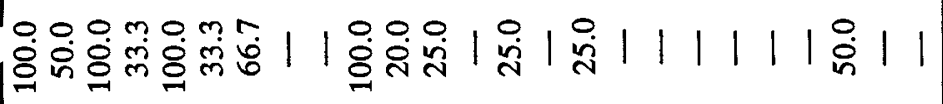 & $\begin{array}{l}\infty \\
\dot{\sim} \\
\dot{n}\end{array}$ & 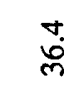 \\
\hline \multirow{2}{*}{ 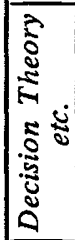 } & $\stackrel{2}{2}$ & 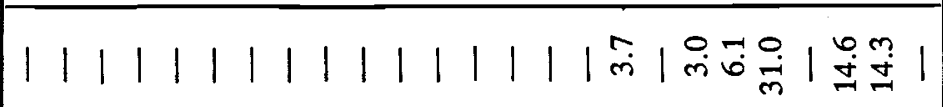 & 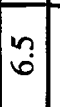 & iे \\
\hline & $\Xi$ & 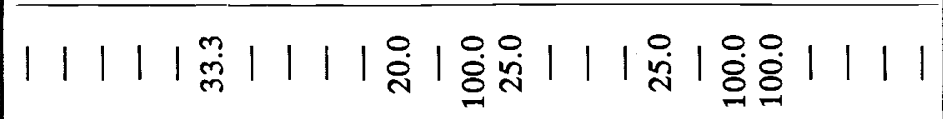 & $\left.\begin{array}{l}\infty \\
\dot{\sim} \\
\dot{\sim}\end{array}\right]$ & ֻัن \\
\hline \multirow{2}{*}{ 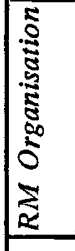 } & ₹) & : & $\bar{q}$ & $\underset{m}{\stackrel{d}{m}}$ \\
\hline & $\Xi$ & 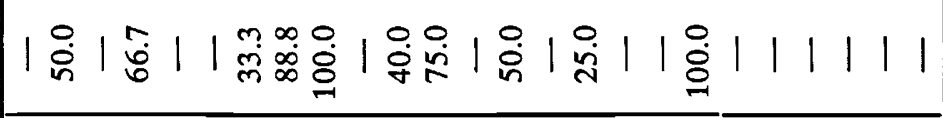 & $\overrightarrow{\dot{q}}$ & $\frac{\text { mें }}{m}$ \\
\hline \multirow[t]{2}{*}{$\cong$} & $\underset{2}{2}$ & 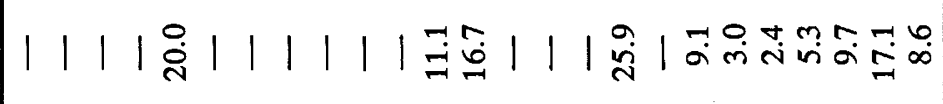 & 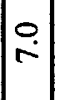 & in \\
\hline & 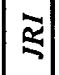 & 1111111111111111111111111 & 1 & 1 \\
\hline \multirow{2}{*}{ } & ș & $\mid$ mo & $\stackrel{\stackrel{\rho}{ \pm}}{-}$ & 荬 \\
\hline & $\Xi$ & 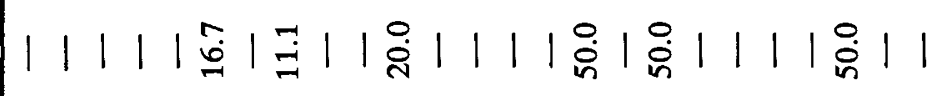 & $\stackrel{-}{\sim}$ & aे \\
\hline \multirow[t]{2}{*}{$\stackrel{2}{2}$} & ฉี่ & 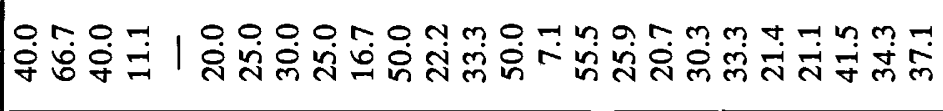 & 节 & @ìn \\
\hline & 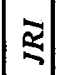 & 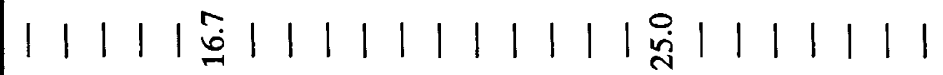 & ing & i \\
\hline & & 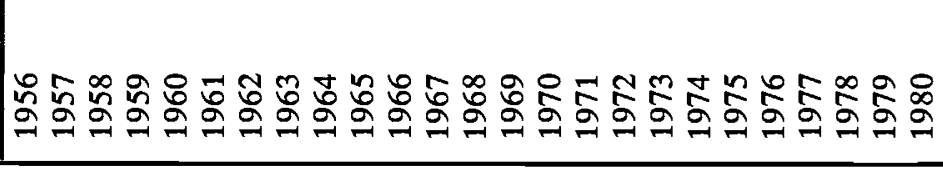 & $\begin{array}{l}\infty \\
0 \\
0 \\
\vdots \\
2\end{array}$ & 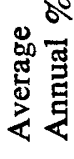 \\
\hline
\end{tabular}


managers. By the end of this period risk management education, at least in the United States, was beginning to be taken for granted, and so diminished as a subject of topical interest.

Papers in the field of decision theory and quantitative methods have figured in the pages of JRI in seven of the years under review, reflecting the way in which neighbouring disciplines will overlap into the risk management field from time to time. It is not until 1972, when the educative phase of the risk management profession had been completed, that Risk Management began to carry articles in this category, indicating that a sufficient number of readers had moved from being concerned with a purely purchasing function to a stage where they were seeking to apply more advanced risk strategies.

Premium minimisation as a topic finds much more representation in Risk Management than in JRI, illustrating perhaps the difference in approach of the publics of the two periodicals. Risk Management is directed chiefly at representatives of the insured, who are obviously more likely to be keenly interested in methods of reducing the amount paid for insurance than readers of JRI, some of whom may look upon the insurance market from a detached, economist's viewpoint, without identifying particularly with either buyer or seller, but most of whom may be expected to have links with insurance companies, the sellers.

In the first half of the review period, this category represented $20 \%$ or more of risk management articles in Risk Management for 10 successive years. Then, in 1967, the figure dropped sharply and was matched by the proportion of articles dealing with captives, a topic which had figured in only one of the previous years. This coincides with the start of the major growth period for the formation of captives, and the subject is ever-present in the volumes for 1974-80, inclusive.

Articles on other forms of self-insurance and premium reduction still feature in these years, but they are now much less frequent than those on loss control.

In the first two years of our survey, loss control articles predominate in Risk Management, but this is probably a reflection of the fact that loss control requires a similar approach whether it is in the service of insurance or of risk management, and in those years when risk management theory was still emergent, articles were written in insurance terms which can now be assimilated retrospectively to risk management. Thereafter, risk management organisation is the predominant theme but until 1965 the proportion of loss control articles lagged behind that in the premium minimisation category. As the rise in interest in captives reduced the number of papers on other premium reduction methods, loss control maintained its presence, and in the final years of the study was rivalling risk management organisation in importance.

This suggests general acceptance of the proposition that "good loss control lies at the centre of any effective risk management programme" (Crockford [3] p. 55). Full or partial self-insurance and other means of reducing premiums are, on the other hand, a less constant feature of risk management, being influenced by the invention of new techniques, fashion (a not unimportant influence in the boom in captive formations in the seventies), and market conditions. It is significant that the proportion of articles in the premium minimisation category in Risk Management falls sharply 
in the seventies as increased capacity led to softer markets in which the bargaining skills of the buyer could be as effective in reducing insurance costs as the employment of specialist risk management techniques.

\section{Conclusion}

Even a very restricted survey such as the present one demonstrates that the literature of risk management has changed in nature and in emphasis as the theory of the subject has been elaborated and disseminated, and as the insurance buyer has gradually made way for the risk manager. Equally, changes brought about by external forces in the insurance market also have their effect on the preoccupations of the literature.

This study has concentrated on literature aimed at the academic and the risk manager. It would be interesting to trace the correlations between changes in the external world and the emphasis of literature intended to introduce the ideas of risk management to managers outside the insurance field.

The history of risk management has yet to be written. This introductory study suggests that the broad outlines of that history could be traced in the literature alone.

\section{REFERENCES}

1. BANNISTER \& BAWCUTT : Practical Risk Management, Witherby, London, 1981.

2. CROCKFORD, G. N.: "The changing face of risk management", Geneva Papers on Risk and Insurance, 2 (August 1976), 10-15.

3. CROCKFORD, G.N.: An Introduction to Risk Management, Woodhead-Faulkner, Cambridge, 1980.

4. GENEVA ASSOCIATION : “Introduction”, Geneva Papers on Risk and Insurance, 2 (August 1976), 3-4.

5. HORRIGAN, W. : Risk, Risk Management and Insurance, Withdean Publications, Hove, 1969.

6. HORRIGAN \& DINSDALE : “The theory of risk", "Analysis of risk", "Methods of handling risk" and "The work of the risk manager", Post Magazine and Insurance Monitor, 13th July, 10th August, 31st August, and 12th October, 1967.

7. McCAHILL, F.X.: “Avoid losses through risk management”, Harvard Business Review, May-June 1971.

8. MEHR \& HEDGES : Risk Management in the Business Enterprise, Irwin, Homewood (Illinois), 1963.

9. ROSENBLOOM, J.S. : A Case Study in Risk Management, Appleton-Century-Crofts, New York, 1972.

10. SNIDER, H. W. : “Reaching professional status : A program for risk management", in Corporate Risk Management : Current Problems and Perspectives, American Management Association, 1956.

11. WILlIAMS \& HEINS : Risk Management and Insurance, McGraw Hill, New York, 1964. 